\title{
In-situ Study of Nb Oxide Thin Films Using Electron Energy Loss Spectroscopy
}

\author{
R. Tao, ${ }^{1}$ R. F. Klie ${ }^{1}$, A. Romanenko ${ }^{2}$, L. Cooley $^{2}$ \\ ${ }^{1}$ Department of Physics, University of Illinois at Chicago, Chicago, IL, 60607 \\ ${ }^{2}$ Fermilab, P.O. Box 500, Batavia, IL 60510
}

$\mathrm{Nb}$, a $4 \mathrm{~d}$ transition metal, as well as its oxides have drawn increasing attention in the recent years due to their intriguing electrical properties. More specifically, $\mathrm{Nb}$ and $\mathrm{NbO}$ (niobium monoxide) are conducting, ( $\mathrm{Nb}$ has the highest $\mathrm{T}_{\mathrm{c}}=9.2 \mathrm{~K}$ of any elemental superconductor), niobium dioxide $\left(\mathrm{NbO}_{2}\right)$ is semiconducting, while amorphous niobium pentoxide $\left(\mathrm{Nb}_{2} \mathrm{O}_{5}\right)$ is insulating. ${ }^{1}$ Thus, the combination of different oxides can change the electrical properties of $\mathrm{Nb}$ devices. Of particular interest to the research perform here is the effect of oxidation on the superconducting properties of $\mathrm{Nb}$ used in superconducting RF cavities. It has been shown that mild baking $\left(120^{\circ} \mathrm{C}\right.$ for 48 hours) of the cavities, to be used in the next generation of particle accelerator, results in a significant increase in the high field Q of the cavity. ${ }^{2}$ It was proposed that a tiny change in the oxidation state of the $\mathrm{Nb}$ surface may affect the character of superconducting $\mathrm{Nb}$ cavities.

In this talk, we will use a combination of Z-contrast imaging, electron energy-loss spectroscopy (EELS) and insitu heating, as well as cooling experiments to examine the atomic and electronic structures of native $\mathrm{Nb}$-oxide thin films on the surface of the $\mathrm{Nb}$ RF-cavities. Using in-situ heating experiments at $120^{\circ} \mathrm{C}$ for 48 hours, we will study the effects of baking on the oxide film structure, and reveal any oxygen diffusion from point defects or grain boundaries inside the bulk Nb towards the cavity surface. Oxygen diffusion has been considered the key to understanding the dramatic change in the RF cavities performance. However, identifying oxygen diffusion on the $\mathrm{Nb}$ oxide surface (normally its thickness is less than $10 \mathrm{~nm}$ ) requires high spatial resolution in EELS, and a good methodology to distinguish the different $\mathrm{Nb}$-oxides. Especially, since $\mathrm{Nb}_{2} \mathrm{O}_{5}$ is amorphous, diffraction cannot be used to distinguish the different oxides. Previously, the chemical shift on $\mathrm{Nb}$ peaks has been associated with a change in the $\mathrm{Nb}$ valence change, and changes in the $\mathrm{O} \mathrm{K}$-edge fine-structure have been used as a "fingerprint" for phase identification. ${ }^{3}$ It is of great interest to further develop the method to quantify the local $\mathrm{Nb}$ valence and hence be able to identify any unknown $\mathrm{Nb}$ oxide composition.

Here, we will present a detailed EELS study of the $\mathrm{Nb}$ M-edge and $\mathrm{O}$ K-edge fine structure for $\mathrm{Nb}, \mathrm{NbO}, \mathrm{NbO}_{2}$ and $\mathrm{Nb}_{2} \mathrm{O}_{5}$ powder samples. Figure 1 shows a clear chemical shift on $\mathrm{Nb} \mathrm{M}_{2,3}$ peak, and a linear relationship between the energy shift and the $\mathrm{Nb}$ valence. Figure 2 shows the near-edge fine structure of the $\mathrm{O} \mathrm{K}$-edge for different $\mathrm{Nb}$ oxidations states and chemical shifts of peaks (b) and (c). Also, on the right side is the linear relationship of the center mass of peak (b) and chemical shift of peak (c). The correlation coefficient in these figures indicates the linear fit matches our experiment very well. The Figure 3 shows our method applied to an unknown oxide area of $\mathrm{Nb}$ sample and the analysis result suggests the $\mathrm{Nb}$ valence is $+4.2 \pm 0.1$

In this presentation, we will show that using this methodology we can quantify the valence change in the $\mathrm{Nb}$ oxide thin film and evaluate the oxygen diffusion during the baking process.

\section{Reference:}

1 E. Z. Kurmaev et al., Journal of Alloys and Compounds, 347 (2002) 213-218

2 A. Romanenko, 13th International Workshop on RF Superconductivity, 2007

3 D. Bach et al., Microsc. Microanal, 15, 524-538 (2009)

4 B. J. Makenas et al., Acta Metall, Vol 30, 469-481 (1982) 
a)

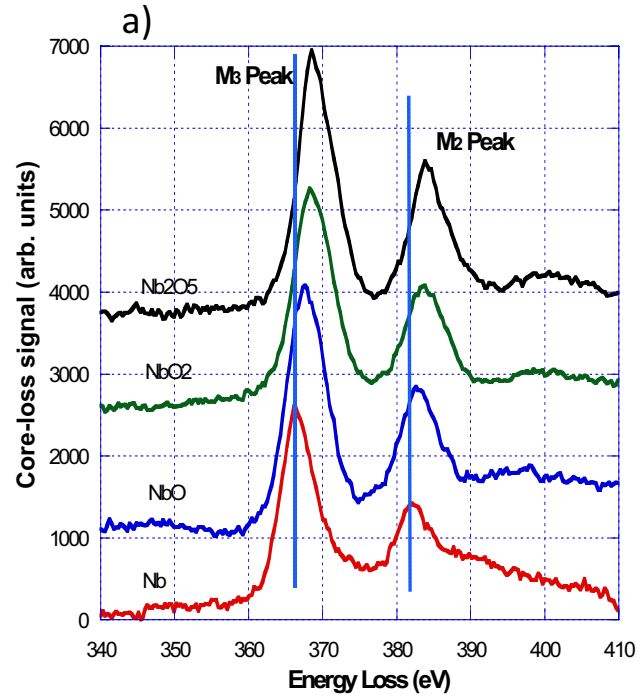

b)

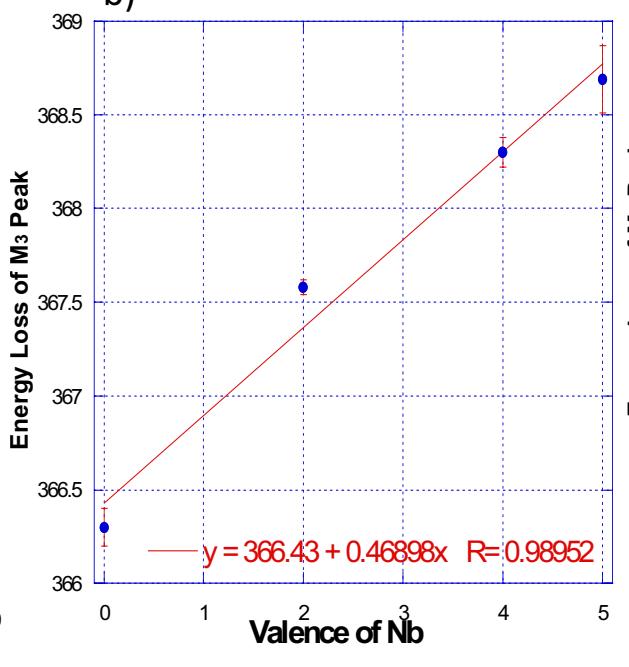

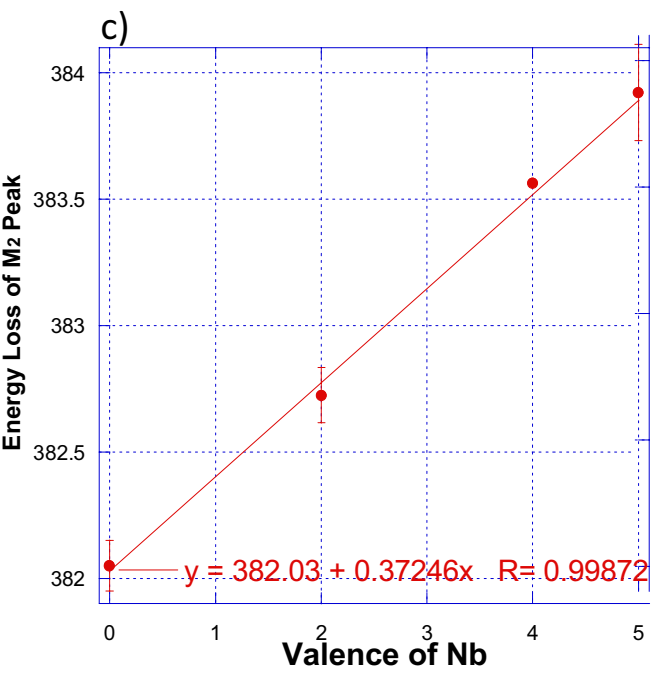

Figure 1: Chemical shift of $\mathrm{Nb} \mathrm{M}_{2,3}$ peak and the linear fit of $\mathrm{Nb}$ valence vs chemical shift.

a)

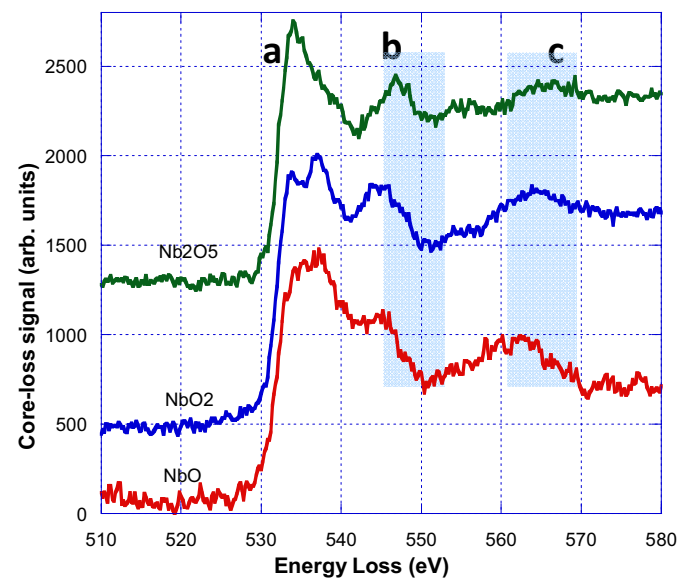

b)

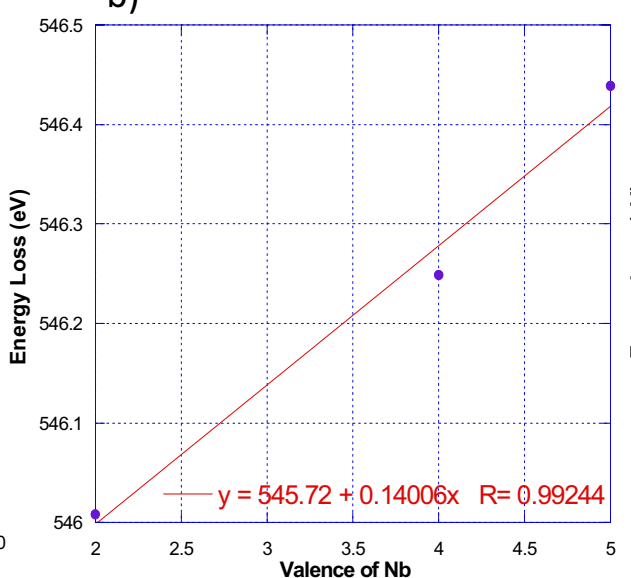

c)

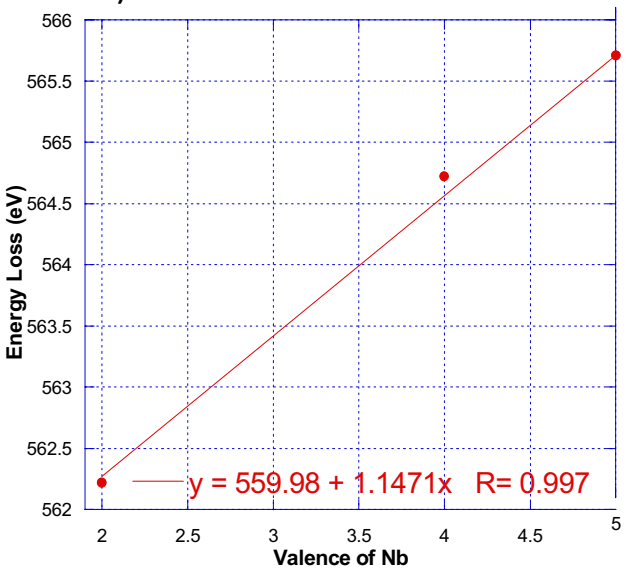

Figure 2: a) O K-edge fine structure for different $\mathrm{Nb}$-oxide samples, b) and c) shows linear fit for $\mathrm{Nb}$-valence vs chemical shift of b) peak $b$ and c) peak $c$.

b)

a)

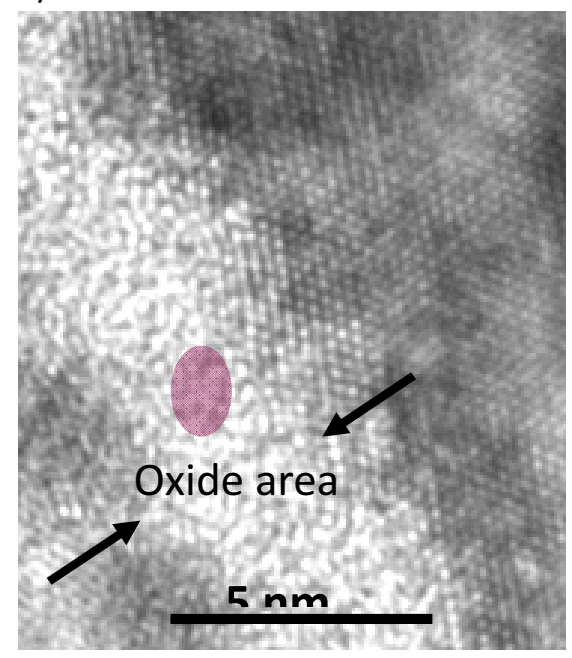

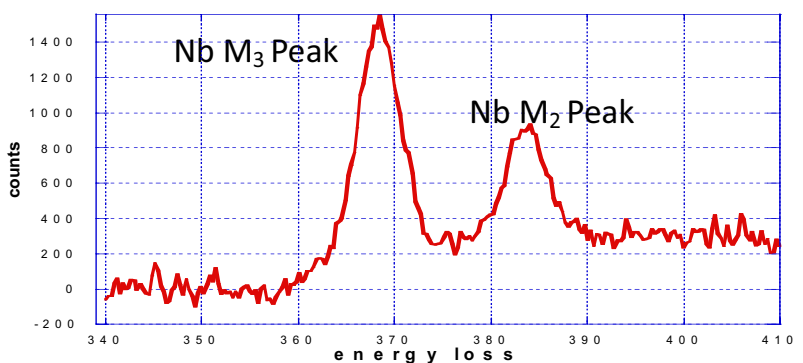

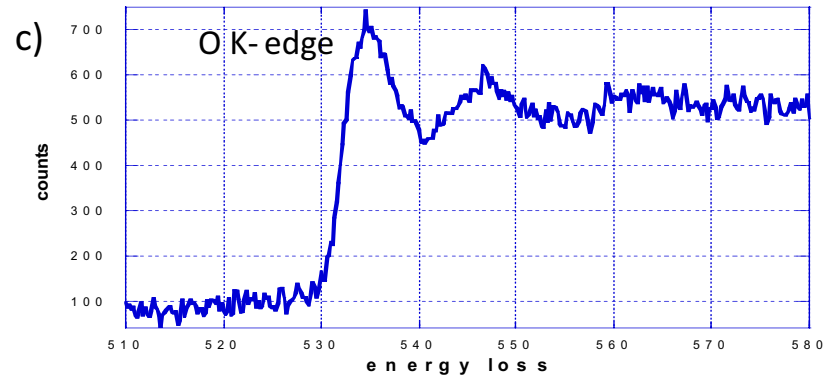

Figure 3: a) Bright-field image including amorphous oxide for a Nb sample, b) and c) EELS spectra taken from the area indicated in a). 